\title{
Automated Quality Control of Pharmaceuticals using Sequential Injection Chromatography (SIC)
}

\author{
Paraskevas D. Tzanavaras*
}

Laboratory of Analytical Chemistry, Department of Chemistry, Aristotelian University of Thessaloniki, GR-54124 Thessaloniki, Greece

The present piece is my third Editorial contribution to the international journal Pharmaceutica Analytica Acta. The first Editorial (http://dx.doi.org/10.4172/2153-2435.1000105e) discussed some potential of automated flow injection techniques in the field of pharmaceutical analysis, focusing on chemiluminescence detection and flow optosensors [1]. The topic of the second Editorial (http://dx.doi. org/10.4172/2153-2435.1000e114) was more specialized discussing the applications of Sequential Injection Analysis (SI) to drug dissolution studies [2]. This third Editorial is also focused on automated flow techniques and will present theoretical and practical aspects of one of the newest members of the family of automated flow injection techniques, namely Sequential Injection Chromatography (SIC).

Despite the hundreds publications using Flow (FI) and Sequential Injection Analysis (SI) reporting the automated analysis of pharmaceuticals, the majority of the methods can be characterized as "single analyte assays" [3]. This is an important drawback of automated low pressure flow techniques, although there are various attempts towards this direction. These reports were in many cases ingenious, but in general were rather complicated or required strictly controlled conditions and were typically based on kinetic discrimination [4], online sample splitting [5] or usage of different detection systems [6]. On the other hand, simultaneous multi-component analysis is critical in many aspects of the quality control of pharmaceuticals. For example there are numerous two- or three-active component formulations (e.g. combinations of antihypertensive and diuretic ingredients). Additionally, purity control and stability testing of pharmaceuticals require per se the usage of analytical techniques with separation capabilities.

The breakthrough in multi-species determinations by FI or SI was made very recently by the incorporation of short monolithic columns to low pressure continuous flow manifolds, introducing the concept of Sequential Injection Chromatography (SIC) [7]. Reversed phase monolithic columns of various dimensions suitable for HPLC applications in many analytical fields were commercialized by Merck in 2000 [8] and were followed by other manufacturers (e.g. Phenomenex). The structural properties of monolithic stationary phases allow efficient separations typically comparable to $3-5 \mu \mathrm{m}$ particulate columns at usually ten-times lower back pressures. This can be achieved by controlling independently the permeability ( $\mu \mathrm{m}$-sized throughpores) and efficiency of the analytical columns (nm-sized mesopores) [9] (Figure 1).

In a typical SIC configuration (Figure 2) a short monolithic column (5-50 mm long $\times 4.6 \mathrm{~mm}$ i.d.) is placed in the flow line between the multiposition valve and the detector. Depending on the used pump (syringe pump or peristaltic) the mobile phase can either flow continuously through the holding coil to the column (peristaltic pump) or can be aspirated prior to every run (syringe pump). Defined volumes of the samples at the microliters level are injected in the usual way in the holding coil followed by propulsion to the column by selecting the appropriate port of the multiposition valve and by reversing the flow direction of the pump. Due to the pressure limitations of conventional SI setups, mobile phase flow rates are typically lower than $1.0 \mathrm{~mL} \mathrm{~min}{ }^{-1}$. Fast separations and short analysis cycles are based on the short length of the monolithic columns, while chromatographic efficiency depends on the selection of the mobile phase and on the properties of the analytes. The interested reader can find useful information on SIC in two excellent review articles that have been published recently $[10,11]$.

Some representative pharmaceutical applications of SIC can be found in Table $1[7,12-22]$. Looking at the methods and the analytical conditions included in Table 1 it is evident that most of the so far reported and published protocols involve separation of simple two/ three component mixtures employing isocratic elution and universal UV detection. To my opinion the potentials of SIC and related techniques can be demonstrated to the scientific community by mainly two ways: (i) by developing SIC methods with gradient elution that will expand the separation capabilities of the technique to more complicated mixtures, and (ii) by exploiting and demonstrating the automated sample treatment potentials of SI combined to monolithicbased separations. Interesting work towards these directions has been carried out by some research groups. For example, Zacharis et al. [23] applied on-line filtration and dilution protocols prior to SIC separation that allowed direct analysis of samples from stress degradation studies of acyclovir (Figure 3) [23]. In 2010 Chocholous and co-workers proposed a two-column SIC setup that enables the separation of analytes with different polarities with isocratic elution [24], while the same research group one year later exploited the potentials of gradient formation in the holding coil by reproducible mixing of two mobile phases [25].

The common denominator of all the SIC procedures mentioned and discussed so far in this editorial was the usage of monolithic stationary phases. Very recently Chocholous et al. [19] reported, for the first time, an interesting alternative that could expand the potentials of SIC [26]. This alternative was the incorporation of short HPLC columns based on the novel "fused core" or "core shell" technology. This technology is

*Corresponding author: Paraskevas D. Tzanavaras, Laboratory of Analytical Chemistry, Department of Chemistry, Aristotelian University of Thessaloniki, GR-54124 Thessaloniki, Greece, Tel: 0030 2310997721; E-mail: ptzanava@chem.auth.gr

Received October 19, 2012; Accepted October 20, 2012; Published October 22 2012

Citation: Tzanavaras PD (2012) Automated Quality Control of Pharmaceuticals using Sequential Injection Chromatography (SIC). Pharmaceut Anal Acta 3:e130. doi:10.4172/2153-2435.1000e130

Copyright: (C) 2012 Tzanavaras PD. This is an open-access article distributed under the terms of the Creative Commons Attribution License, which permits unrestricted use, distribution, and reproduction in any medium, provided the original author and source are credited. 
Citation: Tzanavaras PD (2012) Automated Quality Control of Pharmaceuticals using Sequential Injection Chromatography (SIC). Pharmaceut Anal Acta 3:e130. doi:10.4172/2153-2435.1000e130

Page 2 of 3

\begin{tabular}{|c|c|c|c|c|c|}
\hline Analytes & Analytical Column & Detection & Mobile Phase & $\begin{array}{l}\text { Flow rate } \\
\left(\mathrm{mL} \min ^{-1}\right)\end{array}$ & Reference \\
\hline Salicylic acid/Methyl salicylate & $\begin{array}{l}\text { Chromolith } ® \text { SpeedRod }(50 \times 4.6 \mathrm{~mm} \\
\text { i.d.) }\end{array}$ & UV at $240 \mathrm{~nm}$ & ACN-water $(36 / 65) \mathrm{pH}=2.5$ & 0.6 & [7] \\
\hline $\begin{array}{l}\text { Methylparaben/ Propylparaben/ } \\
\text { triamcinolone acetonide }\end{array}$ & Chromolith $®$ FlashRod $(25 \times 4.6 \mathrm{~mm}$ i.d. $)$ & UV at $243 \mathrm{~nm}$ & $\begin{array}{l}\mathrm{ACN}-\mathrm{MeOH} \text {-water }(36 / 65)+0.05 \% \\
\text { nonylamine, } \mathrm{pH}=2.5\end{array}$ & 0.6 & {$[12]$} \\
\hline Methylparaben/ Propylparaben/ diclofenac & Chromolith ${ }^{\circledR}$ FlashRod $(25 \times 4.6 \mathrm{~mm}$ i.d. $)$ & UV at $275 \mathrm{~nm}$ & $\begin{array}{l}\mathrm{ACN} \text {-water }(40 / 70)+0.05 \% \\
\text { triethylamine, } \mathrm{pH}=2.5\end{array}$ & $0.48-1.2$ & [13] \\
\hline Ambroxol hydrochloride / deoxycycline & Chromolith $®$ FlashRod $(25 \times 4.6$ mm i.d. $)$ & UV at $213 \mathrm{~nm}$ & ACN-water $(20 / 90), \mathrm{pH}=2.5$ & 0.48 & {$[14]$} \\
\hline $\begin{array}{l}\text { Ambroxol hydrochloride / methylparaben / } \\
\text { benzoic acid }\end{array}$ & Chromolith $®$ FlashRod $(25 \times 4.6 \mathrm{~mm}$ i.d. $)$ & UV at $245 \mathrm{~nm}$ & $\begin{array}{l}\text { ACN-THF-0.05 M CH3COOH } \\
(10 / 10 / 90), p H=3.75\end{array}$ & 0.48 & [15] \\
\hline Lidocaine/prilocaine & Chromolith $®$ FlashRod $(25 \times 4.6$ mm i.d. $)$ & UV at $212 \mathrm{~nm}$ & $\begin{array}{l}\text { ACN-0.05 M Phosphate }(40 / 80)+ \\
0.01 \% \text { triethylamine }\end{array}$ & 0.6 & {$[16]$} \\
\hline Naphazoline nitrate / methylparaben & Chromolith $®$ FlashRod $(25 \times 4.6$ mm i.d. $)$ & $\begin{array}{l}\text { UV at } 220 \mathrm{~nm} \text { and } \\
256 \mathrm{~nm}\end{array}$ & $\mathrm{MeOH}$-water (40/65), $\mathrm{pH}=5.2$ & 0.9 & {$[17]$} \\
\hline Betamethasone / Chloramphenicol & Chromolith $®$ FlashRod $(25 \times 4.6 \mathrm{~mm}$ i.d. $)$ & $\begin{array}{l}\text { UV at } 241 \mathrm{~nm} \text { and } \\
278 \mathrm{~nm}\end{array}$ & ACN-water $(30 / 80)$ & 0.48 & [18] \\
\hline Triamcinolone acetonide / Salicylic acid & Onyx® C18 (50 × 4.6 mm i.d. $)$ & UV at $240 \mathrm{~nm}$ & ACN-water $(35 / 65)$ & 0.9 & [19] \\
\hline sildenafil & Chromolith $®$ FlashRod $(25 \times 4.6 \mathrm{~mm}$ i.d. $)$ & UV at $240 \mathrm{~nm}$ & $\begin{array}{l}\text { Ammonium acetate }\left(0.3 \mathrm{~mol} \mathrm{~L}^{-1}\right) / \\
\text { Acetonitrile }(50: 50)\end{array}$ & 2.4 & {$[20]$} \\
\hline Diclofenac & Chromolith $®$ FlashRod $(25 \times 4.6$ mm i.d. $)$ & UV at $248 \mathrm{~nm}$ & $\mathrm{MeOH}$-water $(50 / 50)$ & 2.4 & [21] \\
\hline Amoxicillin and clavulanic acid & Chromolith $\circledast$ FlashRod $(25 \times 4.6$ mm i.d. $)$ & UV at $228 \mathrm{~nm}$ & $\begin{array}{l}\text { Phosphate }\left(25 \mathrm{mmol} \mathrm{L}^{-1}, \mathrm{pH}=3.0\right) / \\
\mathrm{MeOH}(85 / 15)\end{array}$ & 2.4 & [22] \\
\hline
\end{tabular}

Table 1: Representative applications of sequential injection chromatogarphy (SIC) to pharmaceutical analysis.

based on sol-gel techniques to achieve a homogeneous porous layer on a solid core of silica. It provided higher efficiencies due to the smaller diffusion distance and improved mass transfer, lower internal porosity and narrower particle size distribution (Figure 4) [27].

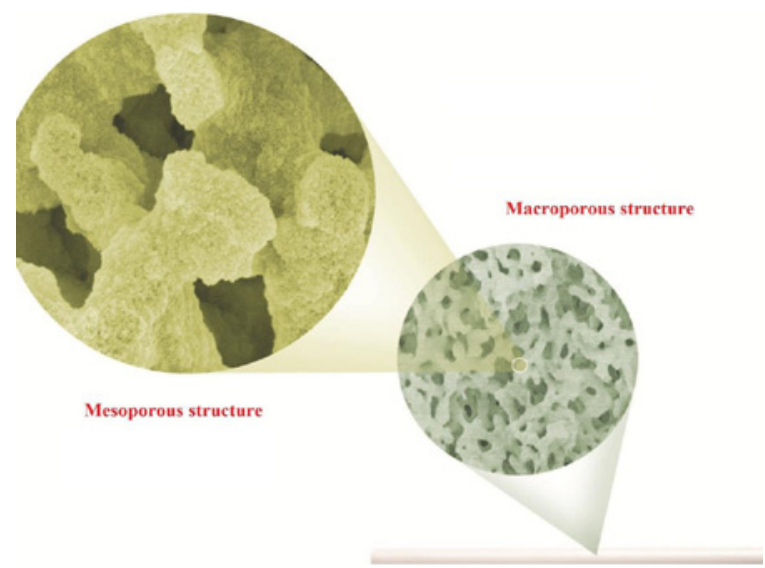

Figure 1: Typical structure of a reversed phase monolithic stationary phase.

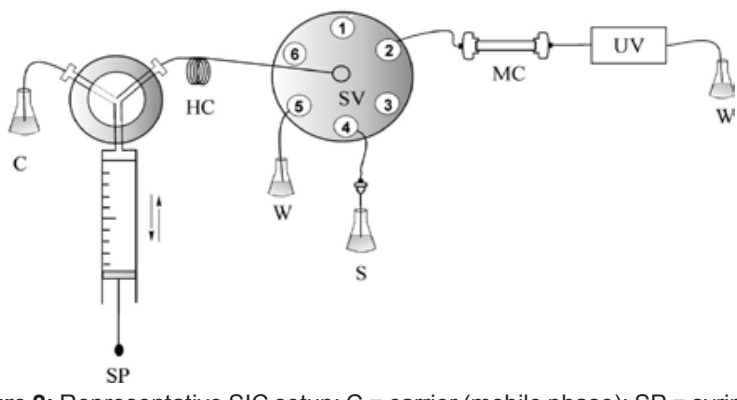

Figure 2: Representative SIC setup: $\mathrm{C}=$ carrier (mobile phase); $\mathrm{SP}=$ syringe pump; $\mathrm{HC}=$ holding coil; $\mathrm{SV}=$ selection valve (or multiposition valve); $\mathrm{MC}=$ monolithic column; $\mathrm{S}=$ sample; $\mathrm{W}=$ waste; UV = detector.

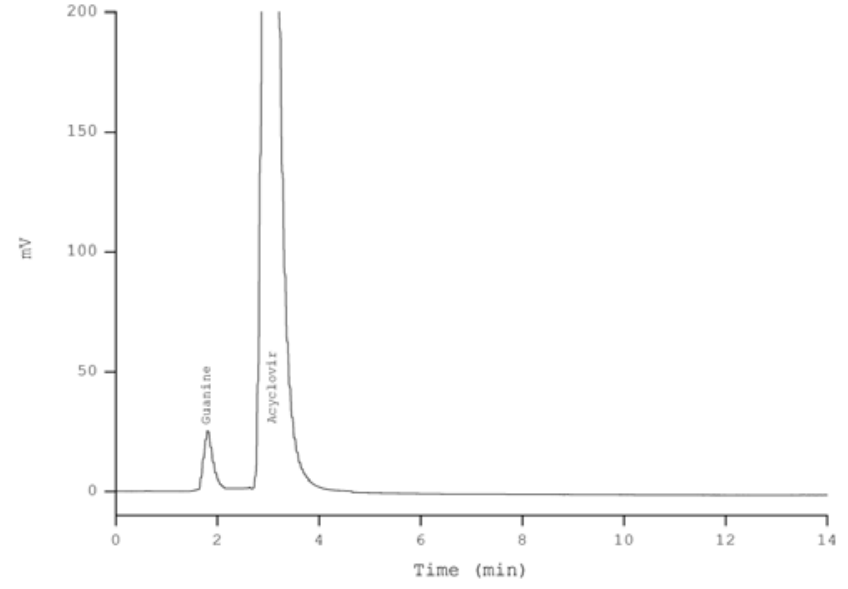

Figure 3: SIC chromatogram of acyclovir and its major impurity guanine (from [23]).

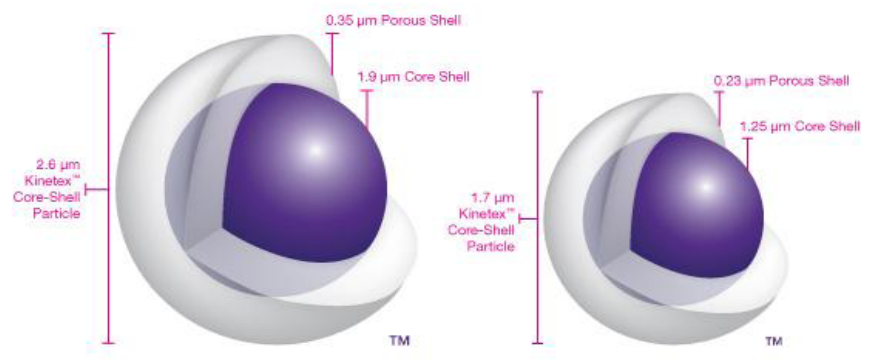

Figure 4: Typical structure of core shell particles (from Phenomenex, Kinetex).

To conclude this editorial SIC is definitely a viable technique that offers enhanced potentials to chemical analysis. To my opinion SIC researchers should not focused on "competing" conventional HPLC to straightforward applications. The real strength of SIC is - as already 
Citation: Tzanavaras PD (2012) Automated Quality Control of Pharmaceuticals using Sequential Injection Chromatography (SIC). Pharmaceut Anal Acta 3:e130. doi:10.4172/2153-2435.1000e130

Page 3 of 3

mentioned above - the possibilities of automated sample treatment (extraction, derivatization, dilution etc) and separation in a single run with a portable and low cost setup. In any case special attention should be paid to present fully validated analytical protocols that clearly prove their potentials to "real world" applications and especially in a demanding industrial environment.

\section{References}

1. Tzanavaras PD (2011) Automated Flow Injection Techniques in Pharmaceutical Analysis: A Useful tool. Pharm Anal Acta 2: 5

2. Tzanavaras PD (2012) Sequential Injection Analysis: A useful Analytical Tool in Drug Dissolution Testing. Pharm Anal Acta 3: 5

3. Tzanavaras PD, Themelis DG (2007) Review of recent applications of flow injection spectrophotometry to pharmaceutical analysis. Anal Chim Acta 588 $1-9$

4. Alonso-Mateos A, Almendral-Parra MJ, Fuentes-Prieto MS (2008) Sequentia and simultaneous determination of bromate and chlorite (DBPs) by flow techniques. Kinetic differentiation. Talanta 76: 892-898.

5. Lopez Pasquali CE, Fernandez Hernando P, Durand Alegria JS (2007) Spectrophotometric simultaneous determination of nitrite, nitrate and ammonium in soils by flow injection analysis. Anal Chim Acta 600: 177-182.

6. Tzanavaras PD, Themelis DG (2002) Simultaneous flow-injection determination of fluoride, monofluorophosphate and orthophosphate ions using alkaline phosphatase immobilized on a cellulose nitrate membrane and an opencirculation approach. Anal Chim Acta 467: 83-89.

7. Huclova J, Satinsky D, Karlicek R (2003) Coupling of monolithic columns with sequential injection technique: A new separation approach in flow methods. Anal Chim Acta 494: 133-140.

8. Cabrera K, Wieland G, Lubda D, Nakanishi K, Soga N, et al. (1998) SilicaROD(TM) - A new challenge in fast high-performance liquid chromatography separations. TrAC Trends Anal Chem 17: 50-53.

9. Guiochon G (2007) Monolithic columns in high-performance liquid chromatography. J Chromatogr A 1168: 101-168.

10. Chocholous P, Solich P, Satinsky D (2007) An overview of sequential injection chromatography. Anal Chim Acta 600: 129-135.

11. Kika FS (2009) Low pressure separations using automated flow and sequentia injection analysis coupled to monolithic columns. J Chromatogr Sci 47: 648655

12. Satinsky D, Huclova J, Solich P, Karlicek R (2003) Reversed-phase porous silica rods, an alternative approach to high-performance liquid chromatographic separation using the sequential injection chromatography technique. J Chromatogr A 1015: 239-244.

13. Satinsky D, Solich P, Chocholous P, Karlicek R (2003) Monolithic columns - a new concept of separation in the sequential injection technique. Anal Chim Acta 499: 205-214.

14. Satinsky D, Santos LMLD, Sklenarova H, Solich $P$, Montenegro MC, et al. (2005) Sequential injection chromatographic determination of ambroxol hydrochloride and doxycycline in pharmaceutical preparations. Talanta 68 214-218.

15. Satinsky D, Huclova J, Ferreira RLC, Montenegro MC, Solich P (2006) Determination of ambroxol hydrochloride, methylparaben and benzoic acid in pharmaceutical preparations based on sequential injection technique coupled with monolithic column. J Pharm Biomed Anal 40: 287-293.

16. Klimundova J, Satinsky D, Sklenarova H, Solich P (2006) Automation of simultaneous release tests of two substances by sequential injection chromatography coupled with Franz cell. Talanta 69: 730-735

17. Chocholous P, Satinsky D, Solich P (2006) Fast simultaneous spectrophotometric determination of naphazoline nitrate and methylparaben by sequential injection chromatography. Talanta 70: 408-413.

18. Satinsky D, Chocholous P, Salabova M, Solich P (2006) Simple determination of betamethasone and chloramphenicol in a pharmaceutical preparation using a short monolithic column coupled to a sequential injection system. J Sep Sci 29: $2494-2499$

19. Chocholous P, Holik P, Satinsky D, Solich P (2007) A novel application of OnyxTM mark monolithic column for simultaneous determination of salicylic acid and triamcinolone acetonide by sequential injection chromatography. Talanta 72: 854-858.

20. Idris AM, Naheid SA, Elgorashe REE, Eltayeb MAH, Al-Akra HN (2011) Reversed-phase sequential injection liquid chromatographic method for sildenafil assay. J Liq Chromatogr Rel Technol 34: 2256-2270.

21. Idris AM, Elgorashe REE, Assubaie FN, Alnajjar AO (2011) Inexpensive green method for diclofenac assay utilizing sequential injection chromatography. Chromatographia 73: 431-437.

22. Idris AM, Elgorashe REE (2011) Sequential injection chromatography against HPLC and CE: Application to separation and quantification of amoxicillin and clavulanic acid. Microchem J 99: 174-179.

23. Zacharis CK, Verdoukas A, Tzanavaras PD, Themelis DG (2009) Automated sample preparation coupled to sequential injection chromatography: On-line filtration and dilution protocols prior to separation. J Pharm Biomed Anal 49: 726-732.

24. Chocholous P, Satinsky D, Sklenarova H, Solich P (2010) Two-column Sequential Injection Chromatography-New approach for fast and effective analysis and its comparison with gradient elution chromatography. Anal Chim Acta 668: 61-66

25. Koblova P, Sklenarova H, Chocholous P, Polasek M, Solich P (2011) Simple automated generation of gradient elution conditions in sequential injection chromatography using monolithic column. Talanta 84: 1273-1277.

26. Chocholous P, Kosarova L, Satinsky D, Sklenarova H, Solich P (2011) Enhanced capabilities of separation in Sequential Injection Chromatography - Fused-core particle column and its comparison with narrow-bore monolithic column. Talanta 85: 1129-1134.

27. McCalley DV (2010) Instrumental considerations for the effective operation of short, highly efficient fused-core columns. Investigation of performance at high flow rates and elevated temperatures. J Chromatogr A 1217: 4561-4567. 